\title{
Colour Categories in Different Linguistic Cultures
}

\author{
Zhanar A. Kaskatayeva', Shara Mazhitayeva², Zhanar M. Omasheva³, Nurgul \\ Nygmetova ${ }^{4}$ \& Zhanbai Kadyrov 5 \\ ${ }^{1}$ Ph.D. candidate, ${ }^{1}$ Buketov Karaganda State University, Kazakhstan \\ ${ }^{2}$ Doctor of Philology, Professor, ${ }^{1}$ Buketov Karaganda State University, Kazakhstan \\ ${ }^{3}$ Candidate of Philology, Karaganda State Medical University, Kazakhstan \\ ${ }^{4}$ Candidate of Philology, Karaganda State Technical University \\ ${ }^{5}$ Candidate of Philology, Professor, M.Kozybayev North Kazakhstan State University, \\ Petropavlovsk, Kazakhstan \\ Correspondence: Shara Mazhitayeva, 28 University Street, 100028, Kazakhstan. \\ Email: s_mazhit@mail.ru
}

\begin{abstract}
The interest in defining color naming culture-specific features in multisystem languages is one of the relevant themes in linguistics. Numerous colors, their names, and symbolic sense are a peculiar reflection of mentality and culture for any nation. When designating nominatively, the ambiguity and multi-functionality of each color become an important part of the socio-mental world view, which has different ways of expression in different languages. The color naming unit peculiarities in multisystem languages, i.e., Kazakh, Russian and English, are the target of the research. The study focuses on the metaphorical and symbolic use of color naming groups in Kazakh, Russian and English. The research material provided a list of color namings, made up of a continuous sampling of definition, phraseological, bilingual Kazakh, Russian and English dictionaries, including fiction books. Based on the material of Kazakh, Russian and English languages, the authors attempted to define meanings of color spectrum most significant components for different cultures. It is wellknown that color namings are an important phenomenon, reflecting the traditions and customs of different peoples. The authors have attempted to examine and describe the criteria for designating colors in a particular society, as well as to determine the role and place of this category in a language system.
\end{abstract}

Keywords: linguistic world view, national psychology, mentality features, meanings and symbols, the world of colors, phraseological units with color naming components.

\section{Introduction}

The studies of culture and its verbalization in the language are given special attention. V. von Humboldt in his famous work "Comparative Anthropology" notes the importance of cultural studies in the context of various language groups, a different vision of objective reality, and, hence, different ways of representing the linguistic world view in the history of civilization. In this regard, the study of "human spirit" image in the language, traditions, customs, myths, i.e., the analysis of perception,

(C) AesthetixMS 2020. This Open Access article is published under a Creative Commons Attribution Non-Commercial 4.0 International License (http://creativecommons.org/licenses/by-nc/4.o/), which permits non-commercial re-use, distribution, and reproduction in any medium, provided the original work is properly cited. For citation use the DOI. For commercial re-use, please contact editor@rupkatha.com. 
cognition, reflection and person's emotional attitude towards the world is still an urgent problem [Humboldt V.,1984, p. 85].

Our study is applied to colloquial linguistics intentionally. Such a study is not of great interest in science as well as in the field of natural sciences and humanities. However, currently, color spectrum studies have not lost their relevance for scientists. The attention of scientists has already been attracted to the composition of color naming vocabulary in the psycholinguistic aspect (A.P. Vasilevich, 1987), the semantic structure (A. A. Bragina, 1986; I. V. Mokiyenko, 1990), color naming stylistic functions in a psycholinguistic description (R. V. Alimpiyeva, 1986), color naming based on comparative historical analysis (N. B. Bakhilina, 1975), a psycholinguistic experiment (L. V. Vasilevich, 1987; R. M. Frumkina, 1984). The linguistic consciousness of the people, the role of color in human life and ethnocultural system of the Russian language have been investigated by $\mathrm{T}$. I. Vendina, 1998 as well.

In Kazakhstan linguistics, the concept of color is actively studied by F. N. Dauletov, A. T. Kaydarov and G. A. Kazhigaliyeva, whose works are devoted to the analysis of ethnolinguistic, linguistic and cultural color naming peculiarities. One of the latest studies of Kazakhstani linguists in the field of color naming is such multi-year research by Doctor of Philology Sh. K. Zharkynbekova as "Concepts of color in the Kazakh and Russian linguistic cultures" [Zharkynbekova Sh.K., 2011].

The study of color linguistics theoretical aspects is related to the scientific direction of "color linguistics". Linguists distinguish a comparative historical study of color vocabulary (evolutionary direction), the psycholinguistic component of color names, cognitive aspects, linguistic-cultural, and nominative terminological aspects of color vocabulary.

A particular interest of scientists in this field of scientific research is drawn to the fact that there are such concepts as "Linguistics of color", "Semantics of color", "Colorative linguistics", "Color linguistic world view”, etc. when studying color terms in modern science.

Thus, the analysis of theoretical material related to the problems of studying color namings showed that color linguistics as a scientific discipline in its own right has a strong theoretical and methodological base. In this regard, it is difficult to disagree with the opinion of V.G. Kulpina in her "Concept of color linguistics as an independent scientific paradigm in modern linguistics", since it is increasingly acquiring specific features [Kulpina V.G., 2002, p. 7].

The active development of such directions in modern linguistics as cognitive linguistics, psycholinguistics and cultural linguistics has allowed scientists to study the facts of the language concerning the national values of the people, their culture, religion, mental structure as well as mental and worldview features.

\section{Methods}

Recently, studies of color namings in the linguocultural paradigm have become particularly important. The prospect of using the method of cultural linguistics interpretation in linguistic research is undeniable since this method allows us to restore those semantic transformations with great objectivity that reflect a naive world picture corresponding to a particular era, reconstruction of mental attitudes and a worldview system as a whole.

The methods of semantic, contextual and comparative analysis were used to define the semantic color content, study color naming functioning in literary texts, and identify matchings and differences. 


\section{Results and discussion}

Color is one of the cultural principles, which can serve as a "distinctive development model, reflecting the ways of formation, acquisition and consolidation of both common and culturesignificant concepts in cultural memory" [Zharkynbekova Sh. K., 2004, p.110]. Color is surrounded by a whole system of associations, different meanings and numerous interpretations. Therefore, the color becomes a real embodiment of diverse moral and aesthetic values. The significance of color semantics as a cultural component for each nation has a complex and diverse sacred system of meanings, interpretations, and becomes the embodiment of certain cultural values since this is due to historical and cultural, religious, climatic, environmental and other characteristics.

Therefore, color namings are linguocultural and logical phenomena [Bayramova L., 2004, p. 48; Baran, Zimomrya, Bilous and Zimomrya 2008]. Both linguists and ethnolinguists came to a common conclusion, that there are some universal similarities in color naming order. The opinion of E.M. Vereshchagin and V. G. Kostomarova is of great importance. They note in their famous "Linguistic theory of words" that metaphors, idioms and proverbs are used for a certain color and its various shades. They can provide information on the past socio-historical as well as the emotional-mental state of each people [Vereshchagin E. M., Kostomarov V. G., 1980, p. 67]. An interesting remark is made by G. K. Kortabayeva, who believes that the use of the same color namings in lexical and phraseological units of different languages arises due to the use of basic and important colors in the ethnic group's life: “The dominance of the same color names in lexical and phraseological units of different languages is due to the fact that these are the most important colors in the lives of people of a certain ethnic community: "If we want to understand each other, then such words as black, white, red, yellow, green and blue are sufficient for expressing our feelings as the top names" [Kortabaeva G.K., p.16].

According to the scientific studies by A.T. Kaydarov, A. T. Umirbekov and Z. T. Akhtamberdiyev, who have been examining color in the Kazakh language, there are no pure colors in nature free from impurity, except for white and black. While analyzing the colors peculiar to a steppe fauna, scientists became convinced in need to use "main color" and "its shades" according to tradition. In addition, having experimented, they found that a mixture of the main seven colors (or ten) in different volumes and correlations contributes to the formation of individual certain colors [Kaidarov, Umirbekov and Akhtamberdieva 1986, p.45]. According to Academician A.T. Kaydarov's viewpoint, who studied color namings in the Kazakh language from a new perspective, there are more than one hundred and fifty color namings, consisting of one syllable, formed according to the subject basis principle [Khaidarov A.T. and \&,1998, p. 53]. These include blood red, cherry red, bright red, golden yellow, sky blue, iron black, etc. The scientist suggests that, in the future, there would be further enrichment of compound adjectives in the Kazakh language, expressing complex shades of the color spectrum. As an aside, in Russian, adjectives formed by this model are also marked: coffee, bloody-red, milky, salad, lilac, terracotta, heavenly, mustard, etc. However, in the author's opinion, they are much fewer in the Kazakh language.

Scientists believe that the number of "color terms" in a particular language depends on the economic and cultural development of the country, the degree of isolation and other extra-linguistic factors. Researchers built the following hierarchy of eleven primary colors: $\{$ black, white $\}+\{$ red $\}+$ $\{$ green, yellow $\}+\{$ blue $\}+\{$ brown $\}+\{$ gray, orange, pink, purple $\}$. Thus, this whole set is used in the English language: black, blue, brown, green, gray, orange, pink, purple, and red, white, yellow. Unlike all European languages, the group of basic color terms in the Russian language does not consist of eleven primary colors, but twelve, because two main names are used to designate blue color, i.e., blue and light blue. 
Academician A.N. Kononov's scientific investigations have become the first works on studying color naming semantics in the Turkic languages. Such A.N. Kononov's works as "On aq and qara word semantics in Turkic geographic terminology" and "Color naming semantics in Turkic languages' terminology" can be related to the study of this point. They examine "aq" and "qara" word semantics, found in the geographical terminology of Turkic languages, as well as color naming meaning peculiarities. In these works, the author studies the methods for color naming unit formation and their meaning among the Turkic peoples [Kononov A.N, 1954; 1975].

Like in other languages, phrases associated with color naming in Kazakh can be referred to such groups as nature, human, social system, traditions, customs, rites, etc. Since the Kazakh people in ancient times belonged to the nomadic peoples, their livelihoods were closely connected with nature. The nomadic peoples' aim was not to subdue nature but to live in peace with it. This understanding came from the experience acquired. Moral, cultural and ethical principles have developed in such a way.

In addition to the direct meaning of color, there is also its figurative meaning, e.g., white in Kazakh culture means humanity, innocence, good intentions, sincerity, justice, truth, kindness, prosperity, holiness, a girl's beauty, respect, honor, gentlehood, showing joy in honor of some event, foolishness, unwillingness to do hard work, weakness, loss of strength and this color is known as a noble, worthy, pleasant, and warm color. "Even if I'm honest, do you want to denigrate me? Tell me if he is not honest! What do you say if he turns out to be honest, innocent?" [Auezov M., 1979, p. 87].

In Russian, the word white has such derivative meanings as "light" (white wine), "clear" (in broad daylight), "clean" (a white room), "unusual" (a white crow), "an extreme degree of anger" (on a tear), "obvious" (transparent), "relating to the nobility" (of noble birth), "not doing hard work" (a person shirking rough or dirty physical work), "unknown, strange" (blind spots).

The white color in the English linguistic world view is often associated with honesty, virtue, kindness, joy, divinity, sanctity, ultimate wisdom, a dream and a spent life. Such an expression as "whiter than white" is (sometimes ironically) used when talking about a person who is characterized by complete moral honesty and follows moral standards. The bride at her wedding is most often dressed in white ("a white wedding") since the white color traditionally stands for her purity and virginity. In addition to positive associations said above, we also met a negative meaning connotation: "a white elephant" (the King of Siam, wishing to ruin any of his subjects, presented him a sacred white elephant, a housing of which was very expensive); "cowardice, faint-heartedness" (show the white feather), "confession" (put on a white sheet; stand in a white sheet).

When analyzing color namings in different languages, we face the fact that many color adjectives both have common color meanings and give a qualitative description, a person's spiritual and emotional qualification and his life. For example, in the Turkic languages, the "white" color naming has such lexical and semantic variant as "honor, good": aq niet means "honorable intention" (verbally "white intention") and aq jol means "good luck!" (verbally "white way"). As a rule, white color symbolizes purity, innocence, virtue and divine light in the Christian tradition. White flags were hung out as a sign of the warfare end. Besides, most Slavs and Europeans associate the white color with the ideas about cleanliness, innocence, marriage, as well as hospital and death (the native speakers of most Turkic languages associate this color only with cleanliness).

Black is opposite of white. Along with white, black is one of the most important components of traditional cultures' color palette. It symbolizes all the darkest, secretive, evil, darkness, grief, death as opposed to white. Black as a shadow of white invariably accompanies it everywhere. 
The academician A.N. Kononov, the first to study color name meanings in Turkic languages, defined twenty different meanings of black in the adjective. Black color means not only darkness, piercing cold, thick, large, strong, ferocious, variety, mediocrity, suspense as well as difficulty, difficult experiences, poverty. Some scientists examine names associated with black, by dividing them into six groups: 1) evil; 2) misdeed, cruelty 3) primacy 4) holiness, nobility 5) simplicity 6) sadness and gloom [Kononov A.N, 1975, p. 63].

The analysis of the Kazakh phrase book showed that a "black" lexeme is used to express the following meanings: "dark, not bright", "strong, biting” (about wind, frost: qara jel - chilling wind; qara suyq - biting frost); "large, big" (about cattle: qara mal); qara ter - excessive sweat, qara kush - strong, qara qurymdai - lots of; "honored, iconic" (a revered house); "wealth"; "the only, the closest and dearest"; "of humble origin" - qara suek; "insipid, lent food" - qara keje; "severe" - qara jurek; dishonest - qara kenil; "prose, words of wisdom" - qara sez; "teaching reading and writing" qara/hat tanu; "disgraced" - qara bet; "fairness" - qaq jary; "beauty" - Qaraqat - a girl with black beautiful eyes; "sadness, bad luck" - qara aspandy jaýǵa aldyrý - to fail; "damnation, wish evil”.

In Russian, the word "black" may be socially colored in the meaning of "honorless" in comparison with "white" - "honorable": "commoner" (compare: "of noble birth"), "treat as a slave", "black people", "lower classes". The interesting fact about the last two examples is that, according to Yu.S. Stepanov's research, "Black people" in the XIII-XV ${ }^{\text {th }}$ centuries were called the middle-class members (lower class), who were not personally dependent on the top-class members - "service class people". Among the "Black people" were the members of both urban and rural populations. The pre-existing concept of "smerd" was applied to the farmers. Yu.S. Stepanov traces the connection between the word "smerd" (a person sitting on the ground; a peasant) and the meaning "black" in Indo-European languages and explains this by slash-and-burn agriculture of that time, in which forest cutting and burning was used to clear the land for seed: the word "smerd" as the farmer's name could be associated with the meaning "black from fire, from forest burning" [Stepanov Yu.S.,2004, p.684-685]. Later, social inequality, accompanied by peasants' increased serfdom, led to a change in the meaning of "black people" to "common people (commoners)".

In addition, black is a color that is imagined by a person in his way: the color of the earth, a sign of affluence. This is a philosophical concept which means constancy including such fixed phrases as: "bare earth", “common people”, “wicked weapon”, "black horse", "maid who does labor".

From the mythological viewpoint, light and dark parts of the day are synonymic to light and dark, "good" and "evil" spirits. In Russian, "Black Day" is combined with "evil hour" and "hard times" in the phraseological context. Black can be used to express negative human qualities: "black heart", "black thoughts".

In Russian, the direct meaning of the black lexical unit is "soot color". In English, black is "the color of night and coal", i.e., the standard of black is the color of night or coal.

In the English language, the word "black" has a large number of meanings. For example, "a black sheep" means the ill-being of a family member, society. In the Middle Ages, England was Europe's largest wool producer and exporter. The quantity and quality of wool determined national economic well-being. A black sheep in a flock meant that its wool was unprofitable since it could not be dyed in different colors. Therefore, in Russian, there is still an expression "a black sheep". In the English heraldry, "black" also means constancy and freedom, the ability to anticipate developments. In the British court, a judge tore squares of black cloth when pronouncing capital punishment. The Black Act is a decree against deer hunters in the early XIX ${ }^{\text {th }}$ century. The hunters blackened their faces to be disguised. Black Acts are the Acts of the Scottish Parliament for which 
black illustrations were created in the middle of the XVI ${ }^{\text {th }}$ century. Black Parliament is the Parliament under Henry VIII. The Black Book of admiralty is the British Navy Code of the XIV ${ }^{\text {th }}$ century. Black Republican is a nickname given to the Republican Party of the United States by the freedom from slavery supporters in those states where it was not entered earlier in the XVII ${ }^{\text {th }}$ century. The Black color is a symbol of power. "Black Rod" with a lion; the King-of-Arms is a permanent official in the House of Lords who is appointed by the monarch and invites the Members of the House of Commons to the monarch's throne speech. This title has been in Great Britain since 1350. Black Rood of Scotland is the piece of the True Cross, set in an ebony crucifix, left to the Scottish people. The crucifix was lost during the Reformation (the XVII ${ }^{\text {th }}$ century). The Black color is associated with the election procedure. Black Book is a black cover book that recorded the churchmen's violations in monasteries (the XVII ${ }^{\text {th }}$ century). Black dog is a small tin coin during the reign of Anna. Black Books of the Exchequer is a document containing information about the king's finances (mid-XIII ${ }^{\text {th }}$ century). Black Doll is a doll in a port shop window, which indicated that clothes could be handed over to the shop for money. Black lists are bankruptcy lists secretly made by businessmen. Blackmail is money paid to robbers in exchange for stolen property. To levy blackmail means as follows: 1) to lay under tribute; 2) to set excessively high prices for cabs during the Great Exhibition in London (the XIX ${ }^{\text {th }}$ century). Black money is fake coins imported into England and forbidden by Edward III in the XIV ${ }^{\text {th }}$ century. Black Flag is a pirate flag, also known as "Jolly Roger". Black Flags are pirates in the China Sea, who fought the French in Tonquin [Isina G.I., 2007].

The "basic" color names are paradoxical, and therefore, the semantic range of color namings contains both positive and negative components. For the languages studied, white is associated with something positive compared to black. Therefore, positive connotation dominates in the semantic range of white and negative in black semantics.

We can talk quite definitely about the symbolic use of white-black and the light-darkness binary oppositions, correlating with them, and accordingly, with the opposite meanings of "goodbad", "good-evil" ("white day, black night") in the studied cultures.

The red color is one of three colors, which are "abbreviated or concentrated designations of psychobiological experience large areas affecting both the mind and all senses". In traditional cultures, this color is certainly given special attention. The word "red" goes beyond common color designation. In most ethnic cultures, red is the equivalent of something beautiful, wonderful. In the Russian language, the adjective "red" had the meaning "beautiful", and this meaning has been preserved in many fixed expressions: krasna devica (a pretty girl), krasniy molodets (a handsome boy), krasno solnyshko (a gorgeous sunshine), etc.

At all times, red was particularly popular because its effect was very strong compared to other colors. In almost all nations, red is associated with fire and blood. The red color has become the main heraldic color. The red banner symbolizes rebellion, revolution, independence. Healing properties were attributed to this color and it was used in conspiracies.

In the ancient Turkic language, the color could be referred to the four winds: red - south, black - north, white - west, blue - east. Due to the fact that red is considered a fire sign, it has the meaning of a sacred color. In ancient times, Kazakh people followed such customs as worshiping the sun, therefore, the symbol of the sun was taboo: the fire was not talked about, spitted, extinguished with water, trampled, and personal purification was performed with it. A burning bonfire inside the yurt (nomad's tent) was a sign of unity, prosperity, and procreation. That caused the formation of such words as a newlyweds' yurt, a young family and a family. In modern Kazakh, the "red" color has become the basis for such words' origin as turn red, young, frolicsome, a beautiful-looking girl 
[Kaydarov A., 1998, p. 43]. According to Kazakh tradition, the red color stands for a person's negative qualities as well: "qyzyl kóz" - a backbiter, and indicates natural phenomena and processes (qyzyl jel - "a strong wind").

The red color and all its shades are considered to be extremely popular in the Russian cultural and historical tradition. Therefore, a positive connotation dominates in phraseological unit meanings. For example, "red sun", "red yard", "red word" and "red days" are a period of luck and good life (as opposed to "dark days"). The short form of the adjective "red" is used in folk speech and poetry to mean something good, bright, and light. The word "red" is also associated with something honorable, respected (a place of honor). This lexeme is found in reality word combinations referred to some social events, holidays: "a red-letter day" (public holiday).

At all times, the red color was very popular because its effect was much stronger in comparison with the others, and therefore, it is identified with fire and blood. It stood for a ban and danger warning. The red color has become the main heraldic color. The Red Banner symbolizes rebellion, revolution, independence. This color had healthfulness and was used in conspiracies.

The word "red" is represented by the following phraseological units: 1 . "to be in the red" - "to be in debt"; 2. "come out of the red" - "get out of debt"; 3. "go into the red" - "bring deficit"; 4. "put in the red" - "lead to bankruptcy"; 5. "as red as a beet" - "red, purple”; 6. "as a red as cherry" - "ruddy"; 7. "as red as fire" - "flame-colored".

In modern English, red is emotionally charged. It is related to the male principle, the energy of life, war, aggression, danger, impulse, emotions, passion, vitality, health and youth. In the XIX ${ }^{\text {th }}$ century, the red color was considered the color of revolution among the English and French socialists. Red republicans are French radical republicans who have stated that they would not dirty their hands with blood to achieve their political interests. The headgears of red color have become their distinctive mark. However, this color is often used to express psychological quality associated with something indecent, immoral, shameful: to get/have a red face; to give someone a red face; to become red in face. In the English language, red on white can express bloodshed and deathly pallor. In the Catholic tradition, red is a symbol of Christ's sacrifice. He has become a symbol of the Lord's soldiers - crusaders, cardinals and pilgrims. Holidays and saint's days are marked in red in the calendar. Red is the color of the British monarchy. In honor of Queen Elizabeth II, the red carpet is specially laid out for her during visits. Hence the expression comes "to roll out a red carpet". Red is often associated with gold. "A red kettle" means "gold watch", but in thieves' Latin, it means "stolen watches". Red Book of the Exchequer is the English monarch's income book. The tradition of drafting such a document began during the reign of King Henry II in the middle of the XIII ${ }^{\text {th }}$ century. Red boo is torture borrowed from nomads when a prisoner was incised over his ankles and ripped off his heels. Redbreasts are street messengers, similar to their vest's color.

English red is "the color of blood or fire". These examples illustrate that the difference between Russian color adjectives is that they most often point to one reference object as a carrier of this trait, while English can have several prototypical carriers of the trait.

In Kazakh culture, the blue color symbolises peace and unity, prosperity and life. Blue is the equivalent to the word "creator", therefore; this color was a cult color among the Turks, due to sky worship as Tániri's (God) habitat. Therefore, it is not a coincidence that it means strength, victory, exaltation, superiority, arrogance. Blue expresses people's name, the cosmos, the infinite universe, in which the stars, constellations, planets, galaxies are located. Blue is an ancient Turkic cosmonym. [Kenesbayev S., 1977]. In national ornaments, domes of Turkic minarets, including the Kazakh people, the blue color indicates a special symbolic meaning. 
The record shows that the word kók (dark blue/blue) is mentioned in texts of Ancient Turkic writing as an ethnonym since this color was a tribal alliance symbol: "Kók orda". In this case, the word kók, according to some scholars, did not mean color, but the Ancient Turkic residence. Kók túrks are Eastern Turks. It should be noted that kók in the Kazakh language also means "color of greenery, vegetation”. For example, kók dala (a green steppe), kók maysa (a green grass), kók shalgyn (a green meadow). Phraseological units analysis with "kók" component showed that this color designation has a number of other meanings: thin, fatless, tasteless, angry, rageful, chatterer, lazy, silly. The word "kók" has the following associative field: sky, ocean, grass, endless, steppe, banner, coolness, spring, tea, meadow, light, clear, frost, peak.

In the history of Russian everyday culture, dark blue and blue express good, happiness, embodying all positive: a bluebird of happiness, a pipe dream. The word blue is associated with the following meanings: spring, sky, air, beautiful, bright, delicate, pure, nature, life, flower. In the minds of Russian people, "dark blue" as well as "blue" are associated with the native land, motherland. And only a small number of phraseological units with a "dark blue" component are found in the meaning of "trouble", "disdain". For example, a bluestocking (about a woman dropped into books, having lost femininity).

In English culture, "dark blue" has the following meanings: 1) blue, sky-blue, dark blue; 2) blue with bruising; 3) scared, sad, depressed; 4) obscene, hard-mouthed; 5) conservative; 6) scholarly (about a woman). Dark blue/ blue in English are the symbols of sky, sea, height and depth. Before the battle, Ancient Bretons applied blue tattoos on to the body to frighten the enemy with heavenly wrath. Blue is a symbol of constancy, devotion, justice, perfection and peace. Dark blue/blue is often associated with the greatness of soul and advanced intelligence. In the Catholic tradition, it is the color of sincere love for God and prudence, Divine creation and immortality of the soul. On the other hand, English folklore often mentions blue lights in the night, i.e, the time when ghosts appear. Sometimes blue is used in burial rituals. The coffin of the young deceased is covered with a blue cloth. Blue is a symbol of heart service to God on the angels' images. On the clothes of Mother of God, blue is a symbol of feminine modesty. Deep blue is the color of the Tory Party and is often associated with conservatives.

In the history of Russian everyday culture, the blue color maintained a generally negative connotation for various reasons. The light shade of blue, on the contrary, had the most positive associations. Accordingly, the words designating a blue shade, e.g., "azure" also had a positive coloration.

The difference concerning blue and light blue was reflected in Russian idioms and sayings: "bluestocking" - "stale, callous woman" (bas bleu in French) characterizes a woman who neglected home and family); "saucer with a blue border", "blue dream"; l'oiseau bleu (Fr.) - "bluebird, an unattainable dream". The use of blue symbolism in French also influenced figurative meaning formation. Initially, it was associated with an indefinite distance (blue distance), French - bleu spatial - "deep blue" (spatial), bleu horizon - "gray-blue" (horizon).

The yellow color category in three languages studied is denoted by such a color term as "sary" - yellow. This is the main and neutral color term on the basis of which a dictionary is formed, reflecting shades of yellow. The semantic range of yellow in the languages studied includes both negative and positive components. Positive semantics of yellow is predetermined by its identity with gold, the sun, flowers and dates back to antiquity. Yellow was highly valued among the Turkic aristocracy, and, therefore, it is found in proper names, eg., Sary-bai. In the minds of Kazakh people, this color stands for the native land: sary dala, sary jarlau, sary jazyq; a season - sary kúz (a golden autumn), as well as a long-lasting natural or physiological phenomenon (sary kúz - a long-lasting 
autumn), (sary tósek - a protracted illness); experienced/inexperienced, cunning. [Kenesbaev S., 1977].

According to Kazakh traditions, the young people wore silver rings (white metal) instead of gold rings (yellow metal). Travelers going on a long journey never put anything yellow into their bags so that the road would not be difficult and long.

Yellow is a sign of reason, contentment, restraint. The expressions "patient will be rewarded" and "hope is the last thing to die" with the use of vocabulary denoting yellow, on the one hand, provide comfort and hope. However, on the other hand, they are associated with sadness, grief, depression as well as inexperience: fall into deep sadness, die of sorrow. They additionally mean time length - wait a long time and "corrupt media, a yellow journal" (about the periodical press) as well.

In the English linguistic consciousness "yellow" means as follows: 1) color; 2) conv. cowardly; 3) obs. jealous, envious; 4) a yellow complexion person, as well as a symbol of money, wealth, money-grubbing. Yellow fever is amarillic typhus amarillosis. Yellow stuff is stolen gold/money. Yellow is often the color of illness. The yellow cross was put on plague-infected houses. The Yellow Jack on board ship meant there were infectious patients [Kunin A.V.,1984].

According to G. I. Isina, the variety of native lifestyles is explained by the fact that "the majority of phraseological units have free and temporal word combinations, based on their formation, reflecting objects, phenomena, situations and real facts regarding the particular nation in their semantics" [Isina G.I., 2007, p.85]. V.S. Vinogradov believes that "tribes and peoples, and then nations, go to universal human civilization in two ways: a) through accumulation and exchange of common humanity and products of material and intellectual culture which are available and developing more and more in the society of every people and every nation, since they make certain parts of humanity. And together they represent all mankind; b) through national distinctness, which is accumulated in every people and every nation in accordance with their national and historic development peculiarities, the principle of which is full deployment of truly national characteristic to international and world culture common to all mankind" [Vinogradov V.V., 1977. p.30].

The yellow color as a part of the English phraseological units also has entirely negative semantics. It expresses timidity, cowardice, ill-health: yellow as a guinea (usually related to a face); yellow streak (inclination for cowardice, betrayal); yellow rag (a low-quality newspaper); yellow dog (a weak-kneed person), etc.

As we can see, the role of one color or another for a given ethnic group is reflected to a certain extent in their linguistic consciousness. It should be noted that different ethnic groups perceive colors universally. Researchers draw attention to color perception evolution as illustrated by the brown color. Thus, brown symbolized life among the ancient Egyptians, as it was associated with soil. Among Europeans, it is associated with their "origin", reliability and common sense. This color as well as yellow is considered to be the safest road color. Among some peoples, brown is close to black and dark in meaning, and therefore, is harmonized with frustration and depression. In the Arab-Islamic culture, it was regarded as very negative and was associated with collapse, decay and death. The black (dark) color in psychology is generally considered to be the symbol of denial and protest. Therefore, ultra liberals, i.e., from pirates to anarchists, chose it purposefully. The brown color is regarded as close to black in its aggressiveness. It is no wonder that this color has become "peculiar" for fascists: it is the color of the Nazi attack aircraft uniform. In modern Russian, this color's name is intended to describe everything related to fascism. In Russian culture, brown is traditionally a byword for poverty up. The phraseological units of the Russian language given above 
were recorded in Ushakov's dictionary [Explanatory dictionary of the Russian language, p.119, pp.270-285].

Brown color refers to mixed colors. In many languages, it was initially perceived as a shade of other colors or their mixture. The semantic structure of this color does not have such a wide range of figurative meanings, which is characteristic of other color namings.

Brown color in Kazakh life means poise, politeness. Such phrases as a daily routine, late autumn, a pleasant breeze, a pleasant gentle song, a pleasant voice with a brown meaning have the following meanings: normal, identical, favorable, positive. "A pleasant sound from afar like a cradle of a mother cradles an endless steppe [Kaidarov A., 1998, p.246; Kaskataeva Zh., Mazhitayeva Shara,2018.].

Zere called her grandson to her ... ... and said: - Ainalayyn, my dear (verbally my brown lamb) - and stroked his back" [Auezov M.,1979. p. 298].

In the Russian language, there is no separate name for brown. "Brown" comes from the word "cinnamon". At this stage of color vocabulary development, associations with brown color are most likely caused by such words as "coffee", "nut", "chocolate", "reed", "chestnut"; hence, the colors "coffee”, “coffee with milk”, “chocolate”, "nut”, "reed”, “chestnut”, “camel”, etc., and are included in the synonymic chain of brown categories.

The basic meanings of color adjectives in Russian and English have similar structures. Differences arise only in designating the symbols. For example, the direct meaning of the Russian lexical unit "brown" is described as "dark, brown-yellow (the color of roasted coffee and acorn)". The British consider the ground, tree and coffee to be the standard brown: "brown is the color of ground, wood and coffee".

According to his studies, this word is often associated with as the color with negative shades in Russian peoples' consciousness (bad, ugly, laughter, etc.).

In German, the brown color symbolizes the Nazi movement.

The brown color is associated with fascism in Russian people's minds. It was caused by German pilots wearing brown shirts and going to the front. In history, it was common under the name of "brown plague".

The category of yellow in three languages studied is indicated by the color term sary - yellow. This is the primary and neutral color term, around which a dictionary is formed, reflecting the values of the shades of yellow. The semantic range of yellow in the studied languages includes both negative and positive components. The positive in the semantics of yellow is predetermined by its identity with gold, the sun, flowers, etc.

Yellow is a symbol of light, a color of gold and an autumn time. On the other hand, it is a symbol of illness and death. In Europe, the yellow flag meant quarantine, and the yellow cross meant plague. In addition, yellow was considered to be the color of betrayal. In France, the traitors' doors were yellowed. Currently, "yellow" color naming in many nations is associated with treason, separation, cowardice.

In many languages, blue and green shades collection is often perceived as a single color, even though there is a special word for green (jasyl). Perhaps, this is due to the similarity of adjacent blue and green colors, which are characterized by a weak optical effect or the fact that in the language the term for blue is older than for green. 
The color of grass and leaves is green. The meaning of the Russian lexical unit "green" is described as "the color of grass". In English, green is "the color of grass and leaves", i.e., the standard of green is grass or leaves. It symbolizes youth, fun, hope, volatility and beauty.

We refer a combination of two or more colors to the category of "motley". In Russian, "the motley" category includes the following adjectives and phrases: motley, mixed, multi-colored, multi-shaded, polychrome, spotted, striped, speckled, checkered, polka dot, etc.

Some ethnographic meanings in Kazakh word "motley" are used in the following fixed phrases: do not cause harm, do not offend, act honestly, do not steal, break off relationships, quarrel, part; a rogue and a swindler.

Table 1 Color naming comparative analysis

\begin{tabular}{|l|r|r|r|r|r|r|}
\hline & \multicolumn{3}{|c|}{ Positive meaning } & \multicolumn{3}{c|}{ Negative meaning } \\
\hline Color & English & Russian & Kazakh & English & Russian & Kazakh \\
\hline White & 26 & 6 & 34 & 12 & 19 & 11 \\
\hline Black & 15 & 11 & 24 & 40 & 42 & 48 \\
\hline Red & 11 & 28 & 9 & 38 & 4 & 18 \\
\hline Dark blue/blue & 36 & 22 & 43 & 5 & 3 & 12 \\
\hline Yellow & 4 & 15 & 8 & 19 & 3 & 28 \\
\hline
\end{tabular}

\section{Conclusion}

So, it is indisputable that, in addition to the main ways of forming words with the meaning of color in folk traditions, there are universal color categories, both white and black, and colors that have different lexical and semantic symbolisms for different nations. It is known that this meaning is transmitted from generation to generation. Currently, colors in different languages, due to their symbolisms, have meanings unrelated to color at all or have a distant semantic color matching.

We have attempted a small scientific study of color semantics in a comparative aspect. The present study seeks to reveal the significance of the most important colors in the people's culture based on the Kazakh artworks, allowing to reflect the specifics of the ethnic group linguistic consciousness and national distinctness, which cannot be imagined without the color.

The color namings in the languages studied are systems formed on a field principle and reflecting both common language system qualities (center and periphery) and properties determined by the microsystem features. On the one hand, these are the systems in the center of which there is a word denoting "color". On the other hand, it is a number of microsystems, in the center of each, there is a "primary" color naming. The words related to a seme of a given central color naming are grouped in a certain order around this color naming, i.e., a microsystem of any color category includes several subgroups of color namings that convey various shades. The peripheral object distribution order around a central color naming depends on semantic unit content, stylistic features and a degree of its use as well.

The ambiguity of basic color names in all three languages drives the need to define color; hence there is a large number of words denoting various shades. Color naming microsystems are 
also represented by a large number of different constructions denoting color or borrowed color terms. But color names are not similar according to frequency and significance analysis as well as the ways for creating fixed relations with nouns. An important role in this was played by the natural and climatic living conditions of the ethnic group and its mentality, which led to a difference in the formation and ways for expressing color names (both basic and shadow). The synonymous chains of basic color terms in languages are characterized by the availability of a greater number of synonyms, which is associated with these languages' rich literary tradition and colorative vocabulary functioning diversity.

Our observation allowed us to conclude that the color semantics in Kazakh language culture sometimes fails to give a correct rendering of the Russian language. The methods for Russian and Kazakh color vocabulary formation are different. The main and peripheral components can be different, which are determined by the long-standing living conditions of peoples.

\section{References:}

Alimpiyeva R.V., 1986. Semantic meaning of the word and structure of lexical-semantic group: a case study of adjective color namings in the Russian language / R.V. Alimpiyeva; The Ministry of Higher and Secondary Vocational Education of the RSFSR. - Leningrad: Publishing House of Leningrad State University. $177 \mathrm{p}$.

Auezov M. Collected Works in 20 volumes, 1979. 3rd part. Abai. The epic novel. Almaty: Zhazushi. 424 p.

Baran Ya.A., Zimomrya M.I., Bilous O.M., Zimomrya I.M., 2008. Phraseology: signs of magnitude: [a guide for students of foreign language faculties]. Vinnytsya: Nova Kniga.256 p.

Bayramova L, 2004.Social-linguistic nomination with color concepts. Word. Text. Time. New means of language nomination in new Europe //. Materials of VII international scientific conference / ed. M.Alekseenko, M. Kuchinsk-Szczecin. 478 p.

Bragina A. A., 1986. Vocabulary and culture of the country: the study of vocabulary in linguistic and cultural aspect /A. A. Bragina. Moscow: Russian language. $151 \mathrm{p}$.

Frumkina R. M. , 1984. Color, meaning, similarity: Aspects of psycholinguistic analysis. Moscow: Nauka. $175 \mathrm{p}$.

Humboldt V., 1984, Von Selected works on linguistics. Moscow: Progress. 396 p.

Isina G.I., 2007. Stereotypes and the national linguistic world view: Monograph. Karagandy: KSU Publishing house. 396 p.

Kaidarov A.,1998. Actual issues of the Kazakh language. Almaty, 1998. 304 p.

Kaidarov A.T., Umirbekov B., Akhtamberdieva Z.T., 1986. Colors full of secrets. Almaty: Kazakhstan, 1986. 95p.

Kaskataeva Zh., Mazhitayeva Sh. \& etc, 2018. Verbalization of the concepts «qonyr» and «sary» in Kazakh language. Journal "Bulletin of Karaganda University. Philology series", \#4. p.38-44.

Kenesbaev S., 1977. Phraseological dictionary of the Kazakh language]. Almaty: Gylym. [in Kazakh]

Kononov A.N..1954. On the semantics of the words "white" and "black" in Turkic geographical terminology // Journal AN Taj.SSR, Department of Social Science. Ed.V 1954. pp. 81-86; Color naming semantics in Turkic languages. // Turkological collection. Moscow, 1975. pp. 145-153.

Kortabaeva G.K.,2007. Kazakh onomapoetics: satirical-humorous character names. Author's dissertation thesis work. Almaty.3op. 
Kulpina V.G., 2001. Theoretical aspects of color linguistics as the scientific direction of comparative linguistics: Author`s dissertation thesis work. Doctor of Phil.sciences. Moscow, 2002. 49 p.

Kunin A.V., 1984. English-Russian Phraseological Dictionary. 20,ooo idioms approx. 4 th edition, revised and enlarged, with bookmarks. Moscow: Russkiy Yazyk.

Mokiyenko V. M., 1990. Russian phraseology riddles / V. M. Mokiyenko. Moscow: Higher school. 16o p.

Stepanov Yu.S., 2004. Constants: Russian Culture Dictionary: $3^{\text {rd }}$ ed., rev. and corr. Moscow .Academic project.

Vasilevich A.P. , 1987. Study of vocabulary in psycholinguistic experiment: a case study of color naming in languages of different systems. Moscow: Nauka. $140 \mathrm{p}$.

Vasilevich A.P. , 1987. Vocabulary studies in psycholinguistic aspect: a case study of color namings in in languages of different systems/ ed.-in-chief V.N. Teliya. Moscow: Nauka. 243 p.

Vendina T.I., 1998. Color in ethnocultural system of Russian, Old Slavonic and Old Russian languages // Slavic Almanac M.: Indrik, 1999. - p. 277-304.

Vereshchagin E.M., Kostomarov V.G.,1980. Linguistic and Terrestrial Word Theory. Moscow: Publishing House: Russian Language. 320 p.

Vinogradov V.V. 1977. The main types of word lexical meanings // Selected Works. Lexicology and lexicography. Moscow. P.169, 28.

Zharkynbekova Sh.K., 2004. Language conceptualization of color in the Kazakh and Russian languages: dis. of Dr. of Phil. sciences. Almaty. 265 p.

Zharkynbekova Sh.K., 2011. Color consciousness mentality. Reconstruction of the color picture of the world in Kazakh and Russian linguistic cultures. Monograph. Astana: Master PO. 357 p. 